\title{
D Assessment of Bone Morphogenetic Protein 3 Methylation in Iranian Patients with Colorectal Cancer
}

\author{
Massoud Houshmand ${ }^{2,3}$, Mohammad Reza Abbaszadegan ${ }^{1,4,5}$, \\ Mohammad Amin Kerachian ${ }^{1,5,6, *}$
}

1. Department of Biology, Nour Danesh Institute of Higher Education, Meyme, Isfahan, Iran.

2. Department of Medical Genetics, National Institute for Genetic Engineering and Biotechnology, Tehran, Iran.

3. Medical Genetics Research Center, Mashhad University of Medical Sciences, Mashhad, Iran.

4. Division of Human Genetics, Immunology Research Center, Bu-Ali Research Institute, Mashhad University of Medical Sciences, Mashhad, Iran.

5. Department of Medical Genetics, Mashhad University of Medical Sciences, Mashhad, Iran.

6. Cancer Genetics Research Unit, Reza Radiation Oncology Center, Mashhad, Iran.

\section{* Corresponding Author:}

Mohammad Amin Kerachian, MD Department of Medical Genetics, Faculty of Medicine, Mashhad University of Medical Sciences, Mashhad, Iran Tel: + 985138002413 Fax: + 985138002247 Email: Kerachianma@mums.ac.ir

Received: 15 Mar. 2017 Accepted: 20 Jun. 2017

\section{ABSTRACT}

\section{BACKGROUND}

Colorectal cancer (CRC) is a common cancer that results in outstanding morbidity and mortality worldwide. DNA methylation is one of the most important epigenetic events that is thought to occur during the early stages of oncogenic transformation especially in CRC. The aim of this study was to investigate whether hypermethylation of bone morphogenetic protein 3 (BMP3) in tissue samples is implicated in Iranian patients with CRC.

\section{METHODS}

From fresh frozen tissue samples of 30 patients with CRC, the DNA was isolated, treated with sodium bisulfite and analyzed by methylation-specific polymerase chain reaction with primers specific for methylated or unmethylated promoter sequences of the BMP3 gene. Demographic characteristics of the patients including age, sex, tumor grade, location, stage, and TNM classification were evaluated and the relationship between hypermethylation of the gene and clinicopathological features was analyzed.

\section{RESULTS}

Methylation of the BMP3 promoter was often present in the DNA extracted from the tumoral tissues. A sensitivity of $56.66 \%$ and specificity of $93.3 \%$ were attained in the detection of colorectal neoplasia.

\section{CONCLUSION}

We assumed that solely BMP3 methylation analysis in our population is not sufficient to select the gene as a screening biomarker and it should be considered in combination with other markers to screen for detection of colorectal cancer.

\section{KEYWORDS:}

Bone Morphogenetic Protein 3, Colorectal cancer, DNA Methylation, Epigenetic, Genetic Screening

Please cite this paper as:

Houshmand M, Abbaszadegan MR, Kerachian MA. Assessment of Bone Morphogenetic Protein 3 Methylation in Iranian Patients with Colorectal Cancer. Middle East J Dig Dis 2017;9:158-163. DOI: 10.15171/mejdd.2017.67.

\section{INTRODUCTION}

Colorectal cancer (CRC) is a common cancer that results in outstanding morbidity and mortality worldwide. It is the second leading cause of cancer mortality, and accounts for over 600000 deaths annually. ${ }^{1}$ It is estimated that the global CRC rates will double over the next two decades because of a growing increase in the incidence of the disease in the developing countries. ${ }^{2}$ According to the Iranian Annual National Cancer Registration Report, CRC is the third most common cancer in Iranian women and fifth in men. Its incidence has increased during the last 25 years dramatically. ${ }^{3}$ 
CRC is developed because of genetic and epigenetic aberrancies that are gained during life (environmental, lifestyle), inherited, or both. ${ }^{4}$ The discovery of global DNA hypomethylation in human tumors was followed by the identification of hypermethylated tumor-suppressor genes and recently, inactivation of microRNA (miRNA) by DNA methylation. ${ }^{5}$ Methylated genes are interesting tumor markers because of their relatively high methylation frequency in neoplasms. They have predictable regions, $\mathrm{CpG}$ (cytosine-guanine) islands, in their promoters to become targeted with molecular assays, offering a screening method for cancer. ${ }^{6}$

Screening for CRC in asymptomatic patients can reduce the incidence and mortality of cancer. In the United States, colonoscopy has become the most commonly used screening test. ${ }^{7}$ Although, it has the highest specificity and sensitivity for CRC and adenoma detection, it has the lowest patient compliance rate due to the need of bowel preparation. Additional limitations of colonoscopy are the required expertise, as well as higher costs, invasiveness, availability, and infrequently adverse events resulting from the procedure itself. $^{8}$ An emerging approach to cancer screening involves the assay of tumor-specific DNA alterations presented as CRC genetic biomarkers in bodily fluids from patients with cancer, such as blood, stool, serum, and urine. Genetic biomarkers are beginning to come into routine practice in the management of CRC. ${ }^{9}$ Recently, a significant advance in the screening and care of patients with CRC have been developed by biomarkers, which could accurately identify patients at-risk for CRC development whom might benefit from early and/ or more frequent surveillance for the disease. ${ }^{10}$ Blood-based screening techniques offer a new diagnostic tool for benign and malignant colorectal lesions. ${ }^{8}$ Detection of methylation markers in stool also provides a promising approach for noninvasive screening of colorectal neoplasms. ${ }^{6}$

In the present study, we studied the methylation status of one of the most important tumor suppressors, bone morphogenetic protein 3 (BMP3) gene, in tissue samples from patients with $\mathrm{CRC}$ obtained from colorectal surgery, using methylation-specific polymerase chain reaction. In the case of tissue BMP3 hypermethylation, the BMP3 DNA methylation status of bodily fluids such as blood, stool, serum, and urine from patients with cancer, may be an attractive target for future development of a detection assay for $\mathrm{CRC}$ among Iranian population.
Table 1: Clinical characteristics of the studied subjects

\begin{tabular}{|c|c|c|}
\hline \multicolumn{2}{|c|}{ Age $($ Mean \pm SD $)$} & \multirow{2}{*}{$\begin{array}{c}\mathbf{5 3 . 4} \pm \mathbf{1 3 . 7 1} \text { years } \\
14(46.66 \%)\end{array}$} \\
\hline Sex & Female & \\
\hline & Male & $16(53.33 \%)$ \\
\hline \multirow[t]{3}{*}{ Grade } & 1 & $12(40 \%)$ \\
\hline & 2 & $18(60 \%)$ \\
\hline & 3 & $0(0 \%)$ \\
\hline \multirow[t]{2}{*}{ Location } & Proximal & $4(13.33 \%)$ \\
\hline & Distal & $26(86.66 \%)$ \\
\hline \multirow[t]{6}{*}{ Stage } & I & $3(10 \%)$ \\
\hline & IIA & $20(66.66 \%)$ \\
\hline & IIIA & $0(0 \%)$ \\
\hline & IIB & $3(10 \%)$ \\
\hline & IIIB & $2(6.66 \%)$ \\
\hline & IIIC & $2(6.66 \%)$ \\
\hline \multirow[t]{4}{*}{$\mathrm{T}$} & 1 & $1(3.33 \%)$ \\
\hline & 2 & $4(13.33 \%)$ \\
\hline & 3 & $22(73.33 \%)$ \\
\hline & 4 & $3(10 \%)$ \\
\hline \multirow[t]{3}{*}{$\mathrm{N}$} & 0 & $21(70 \%)$ \\
\hline & 1 & $6(20 \%)$ \\
\hline & 2 & $3(710 \%)$ \\
\hline
\end{tabular}

$\mathrm{T}$ : the size of the primary tumor and whether it has invaded nearby tissue, $\mathrm{N}$ : regional lymph nodes that are involved. (TNM Classification of Malignant Tumors)

\section{MATERIALS AND METHODS}

\section{Clinical Sample Collection}

Samples included 30 fresh frozen cancerous and 30 adjacent normal tissues obtained from the patients with CRC with no underlying disease who had no therapeutic treatment and underwent surgery in three hospitals in Mashhad (Imam Reza, Ghaem, and Omid hospitals) located in the northeast of Iran. Pathology slides from the surgical resection were recalled to confirm the diagnosis of CRC. Inclusion criterion was primary CRC patients (all stages of disease) and exclusion criteria were insufficient or unavailable tumor tissue sample, insufficient clinical information, and family history of CRC. Clinical and pathological features of the patients were extracted from medical records and tumor staging was determined on the basis of the tumor node metastasis (TNM) classification. Study characteristics of these patients are presented in table 1. Approval of this study was obtained from our local ethics committee, Mashhad University of Medical Sciences, Mashhad, Iran. 
Table 2: BMP3 primers sequences, annealing temperature, and product size of MSP assay

\begin{tabular}{|c|c|c|}
\hline Primer sequences & Product size & Annealing temperature \\
\hline Methylated & $146 \mathrm{bp}$ & $66^{\circ} \mathrm{C}$ \\
\hline $\begin{array}{l}\text { Forward: TTTAGCGTTGGAGTGGAGACGGCGTTC } \\
\text { Reverse: CGCGACCGAATACAACGAAATAACGA }\end{array}$ & & \\
\hline Unmethylated & 143 bp & $57^{\circ} \mathrm{C}$ \\
\hline $\begin{array}{l}\text { Forward: TTTAGTGTTGGAGTGGAGATGGTGTTTG } \\
\text { Reverse: AAACACAACCAAATACAACAAAATAACAA }\end{array}$ & & \\
\hline
\end{tabular}

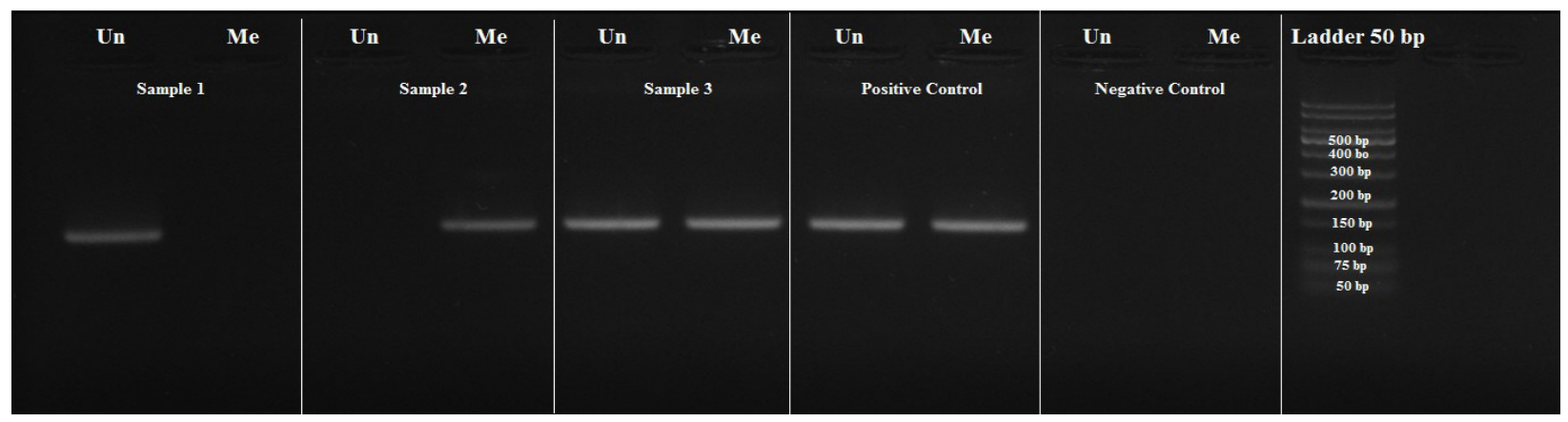

Fig.1: Detection of unmethylated (Un) and methylated (Me) BMP3 in tissue samples of three patients with CRC (samples 1-3) plus positive and negative controls. Product size for the methylated and unmethylated bands is 146 and 143 base pairs, respectively.

\section{DNA Isolation from Tissue Samples}

DNA was isolated from $(20 \mathrm{mg})$ colonic tissues by the use of GeNet Bio tissue kit (Daejeon, Korea) according to the manufacturer's protocol and quantified using Thermo Scientific NanoDrop 1000.

\section{Bisulfite Modification}

DNA was chemically modified by sodium bisulfite to convert all unmethylated cytosines to uracils while leaving methyl cytosines unaltered (EpiTect Bisulfite Kit, Qiagen, Germany) and eluted in $70 \mu \mathrm{L}$ of elution buffer according to the manufacturer's protocol. CG Genome Universal unmethylated DNA (S7822; Vial A; Millipore, Billerica, Massachusetts, USA) and CG Genome Universal Methylated DNA (S7821; Millipore, Billerica, Massachusetts, USA) were used as universal positive controls in our study.

\section{Methylation Specific PCR}

The bisulfite-modified DNA was used as a template for methylation specific PCR (MSP). Methylated and unmethylated primer sequences as well as the annealing temperature and, product sizes are given in table 2. Each primer was designed to contain three or four $\mathrm{CpG}$ dinucleotides so that methylation-specific primers only amplified methylated DNA and unmethylation-specific primers only amplified unmethylated DNA. One microliter bisulfite-modified DNA was amplified in a total volume of $25 \mu \mathrm{L}$ containing $1 \mu \mathrm{L}$ PCR buffer, $1.5 \mathrm{mmol} / \mathrm{L} \mathrm{MgCl}_{2}, 100$ $\mu \mathrm{mol} / \mathrm{L}$ of each deoxynucleotide triphosphate, $200 \mathrm{nmol} / \mathrm{L}$ of each primer, and 1 unit of HotStart Taq (ParsTous, Mashhad, Iran). Amplification included hot-start at $95^{\circ} \mathrm{C}$ for 12 minutes, denaturing at $95^{\circ} \mathrm{C}$ for 30 seconds, annealing at $66^{\circ} \mathrm{C}$ for methylated primers and $57^{\circ} \mathrm{C}$ for unmethylated primers for 30 seconds, extension at $72^{\circ} \mathrm{C}$ for 30 seconds for 35 cycles, and a final 10-minute extension step. All PCR reactions have been performed triplicated to validate the results. The MSP products were then analyzed by $2 \%$ agarose gel electrophoresis shown in figure 1 .

\section{Statistical Analysis}

Statistical analyses were performed using SPSS software for Windows ${ }^{\mathrm{TM}}$, version 15 (SPSS Inc., Chicago, Illinois, USA). Numerical data were expressed as mean \pm SD. Pearson Chi-squared test was used to evaluate the association between the methylation status of the BMP3 promoter in the DNA from all tissue samples, as well as to evaluate the association between methylated BMP3 
Table 3: Relation of methylation status of BMP3 gene between adjacent normal and tumoral tissues and clinicopathological features

\begin{tabular}{|c|c|c|}
\hline Featur & & Results \\
\hline Age $($ Mean \pm SD)* & & $53.4 \pm 13.71$ years \\
\hline \multirow[t]{2}{*}{ Sex* } & Female & $14(46.66 \%)$ \\
\hline & Male & $16(53.33 \%)$ \\
\hline \multirow[t]{3}{*}{ Grade† } & 1 & $12(40 \%)$ \\
\hline & 2 & $18(60 \%)$ \\
\hline & 3 & $0(0 \%)$ \\
\hline \multirow[t]{2}{*}{ Location $\dagger$} & Proximal & $4(13.33 \%)$ \\
\hline & Distal & $26(86.66 \%)$ \\
\hline \multirow[t]{6}{*}{ Stage $\dagger$} & $\mathrm{I}$ & $3(10 \%)$ \\
\hline & IIA & $20(66.66 \%)$ \\
\hline & IIIA & $0(0 \%)$ \\
\hline & IIB & $3(10 \%)$ \\
\hline & IIIB & $2(6.66 \%)$ \\
\hline & IIIC & $2(6.66 \%)$ \\
\hline \multirow[t]{4}{*}{ Tumor invasion $\dagger$} & 1 & $1(3.33 \%)$ \\
\hline & 2 & $4(13.33 \%)$ \\
\hline & 3 & $22(73.33 \%)$ \\
\hline & 4 & $3(10 \%)$ \\
\hline \multirow{3}{*}{$\begin{array}{l}\text { Lymph node } \\
\text { involvement } \dagger\end{array}$} & 0 & $21(70 \%)$ \\
\hline & 1 & $6(20 \%)$ \\
\hline & 2 & $3(710 \%)$ \\
\hline \multirow[t]{2}{*}{ Size† } & $\leq 4$ & $6(13.33 \%)$ \\
\hline & $\geq 4$ & $24(80 \%)$ \\
\hline
\end{tabular}

$* p<0.05 \& \dagger p>0.05$

promoter, tumor location, patient's tissue (cancerous vs. adjacent normal tissue), and demographic variables, such as age, sex, and the TNM classification. A two tailed $P$ value $<0.05$ was considered as statistically significant for all calculations.

\section{RESULTS}

Detection of Methylated BMP3 Gene in Colorectal Tissue Samples

In the present study, methylation status of BMP3 promoter in 60 colorectal tissues (30 tumoral and 30 normal tissues) was studied. The correlation between BMP3 methylation status and clinicopathological features in selected groups is shown in table 3 .

Amongst 30 tumoral tissue samples, 17 samples were methylated, and merely 2 adjacent normal tissue samples were both methylated and unmethylated.

Based on our results, sensitivity of BMP3 was $56.66 \%$ and specificity was $93.3 \%$. Methylation status (tumoral vs. adjacent normal colorectal tissue samples) of BMP3 gene, was significant $(p=0.001)$. Our patients had a mean (SD) age of $53.4( \pm 13.71)$ years. Nearly, $47 \%$ of the patients were female and $53 \%$ of the patients were male. The most common tumor locations were distal (86.66\%), and proximal (13.33\%) of the colon.

There were some significant differences between BMP3 methylation status and the clinicopathological features of the patients $(p<0.05)$. Relation between BMP3 methylation status and several variables is presented in table 3 indicating that there are some significant differences in normal and tumoral tissues between age and methylation and other clinicopathological features. Besides, the highest methylation status was presented in the mean age of 60.8 years. Moreover, the difference in methylation status between men and women was significant $(p=0.0001)$.

There was no significant difference between methylation status and grade of tumor, although most of the methylated tumors were in grade $2(60 \%)$. Furthermore, the difference between stages was not significant, however the highest methylated tumoral tissues were in stage IIA $(66.66 \%)$. There were no difference between methylation status and tumor differentiation and the number of nodes involvement $(p>0.05)$. However, there was a relationship between methylation of the tumor and tumoral tissue size $(p=0.0176)$.

\section{DISCUSSION}

In the current study, BMP3 methylation analysis, which was detected with a sensitivity of $56.66 \%$ and a specificity of $93.3 \%$, indicates its potentiality for early detection of CRC. Studies had shown DNA methylation especially at the promoter region of tumor suppressor genes, as an epigenetic alteration, has an effective role in cancer development. ${ }^{11}$ In recent studies, BMP3 is reported as a high-frequent target of epigenetic inactivation and has a high sensitivity and specificity for CRC, suggesting its utility as a molecular biomarker for early detection. ${ }^{12}$ In 2007, Hongzhi Zou and Jonathan J. Harrington, evaluated the methylation of BMP3 along with vimenten, ALX4 (ALX homebox 4), and EYA2 (Eyes Absent Homolog 2) in CRC. Methylation of BMP3 was detected in $66 \%$ of cancers, $74 \%$ of adenomas, and $7 \%$ of normal epi- 
thelia ( $p<0.01$, cancer or adenoma vs. normal), respectively. ${ }^{13}$ In 2008, Kim Loh and June A provided a molecular and functional data supporting the importance of BMP3 silencing as an early and frequent event in colorectal tumors progressing via the serrated and traditional pathways. The frequent observation of BMP3 methylation in colorectal polyps and cancers, but not in normal mucosa samples, suggests that this may be an attractive target for the future development of molecular blood and/or stool screening tests for the early detection of lesions with neoplastic potential. ${ }^{14}$

Therefore, the clinical application of DNA methylation biomarkers in CRC is rapidly developing into a competitive scientific field and has been noticed by the commercial industry as a marketable product. ${ }^{13}$ In 2014, Cologuard $\AA$, an FDA approved colon cancer screening test, was developed based on detecting methylation of BMP3 and NDRG4 (N-Myc downstream regulated family member 4), as well as considering KRAS (Kirsten ras oncogene homolog) point mutations. It could detect $92 \%$ of cancers and $69 \%$ of the most advanced precancerous polyps in average risk patients. ${ }^{15}$

Based on our results, we assumed that solely BMP3 methylation analysis in our population is not enough to select the gene as a screening biomarker for CRC and it should be considered in combination with other markers. Besides, in our study there was no significant association between BMP3 methylation status and a number of clinicopathological features such as age, tumor invasion, stage, and grade of tumor. Similarly, Hongzhi Zou and colleagues showed there was no association between methylation status with age, sex, tumor size, stage, or grade for any of the four genes including BMP3, which they had studied $(p>0.05) .{ }^{13}$ Loh $\mathrm{K}$ and co-workers also indicated BMP3 methylation was not associated with polyp size and anatomical location. ${ }^{14}$ In addition to $\mathrm{CRC}, \mathrm{BMP} 3$ promoter hypermethylation and its decreased expression occurs in a number of other cancers such as biliary, gastric, and lung cancers indicating BMP3 hyperrmethylation status in cancer. ${ }^{12}$

This study for the first time reveals higher methylation rate of BMP3 in CRC tumors in Iranian population. We recommend further studies to be performed on larger sample sizes and we also suggest conducting prospective cohort studies in the CRC surveillance, which could help determine how this diagnostic tool in a combination with other hypermethylated genes might improve colonoscopy yield and patients' outcomes, and potentially lower healthcare costs.

\section{CONCLUSIONS}

To sum up, the BMP3 gene, as a tumor suppressor, is a high-frequent target of epigenetic inactivation in human $\mathrm{CRC}$, distinctly suggested as a molecular biomarker for early detection; although our study did not confirm that it could be solely used as a biomarker for early detection of CRC.

\section{ACKNOWLEDGEMENTS}

We would like to give special thanks and acknowledgements to our funders, Reza Radiation-Oncology Charity Center. Our sincere thanks also go to Mr Ebrahim Pouladin for his financial support in CRC research and Afsaneh Mojtabanezhad Shariatpanah, Maryam Yassi, Matineh Barati, and Sahar Tavakolian for their technical assistance in this work.

\section{CONFLICT OF INTEREST}

The authors declare no conflict of interest related to this work.

\section{REFERENCES}

1. Lange C, Laird PW. Clinical applications of DNA methylation biomarkers in colorectal cancer. Epigenomics 2013;5:105-8. doi:10.2217/epi.13.4.

2. Delavari A, Bishehsari F, Salimzadeh H, Khosravi P, Delavari F, Nasseri-Moghaddam S, et al. Adenoma detection rates in an opportunistic screening colonoscopy program in Iran, a country with rising colorectal cancer incidence. BMC Gastroenterol 2014;14:196-8. doi:10.1186/ s12876-014-0196-8.

3. Pourhoseingholi MA, Zali MR. Colorectal cancer screening: Time for action in Iran. World J Gastrointest Oncol 2012;4:82-3. doi:10.4251/wjgo.v4.i4.82.

4. Nazemalhosseini Mojarad E, Kuppen PJ, Aghdaei HA, Zali MR. The CpG island methylator phenotype (CIMP) in colorectal cancer. Gastroenterol Hepatol Bed Bench. 2013;6:120.

5. Curtin K, Slattery ML, Samowitz WS. CpG island methylation in colorectal cancer: past, present and future. Patholog Res Int 2011;902674. doi:10.4061/2011/902674.

6. Zou H, Allawi H, Cao X, Domanico M, Harrington J, Taylor WR, et al. Quantification of methylated markers with a multiplex methylation-specific technology. Clin Chem 
2012;58:375-83. doi:10.1373/clinchem.2011.171264.

7. Geiger TM, Ricciardi R. Screening options and recommendations for colorectal cancer. Clin Colon Rectal Surg 2009;22:209-17. doi:10.1055/s-0029-1242460.

8. Tóth K, Wasserkort R, Sipos F, Kalmár A, Wichmann B, Leiszter K, et al. Detection of methylated septin 9 in tissue and plasma of colorectal patients with neoplasia and the relationship to the amount of circulating cell-free DNA. PLoS One 2014;9:e115415. doi:10.1371/journal. pone.0115415.

9. Ewing I, Hurley JJ, Josephides E, Millar A. The molecular genetics of colorectal cancer. Frontline Gastroenterol 2014;5:26-30. doi:10.1136/flgastro-2013-100329.

10. Summers T, Langan RC, Nissan A, Brücher BL, Bilchik AJ, Protic M, et al. Serum-based DNA methylation biomarkers in colorectal cancer: potential for screening and early detection. J Cancer 2013;4:210-6. doi:10.7150/ jca.5839.

11. Sharma S, Kelly TK, Jones PA. Epigenetics in cancer. Carcinogenesis 2010;31:27-36. doi:10.1093/carcin/bgp220.

12. Kisiel JB, Li J, Zou H, Oseini AM, Strauss BB, Gulaid $\mathrm{KH}$, et al. Methylated bone morphogenetic protein 3 (BMP3) gene: evaluation of tumor suppressor function and biomarker potential in biliary cancer. $J$ Mol Biomark Diagn 2013;4:1000145.

13. Zou H, Harrington JJ, Shire AM, Rego RL, Wang L, Campbell ME, et al. Highly methylated genes in colorectal neoplasia: implications for screening. Cancer Epidemiol Biomarkers Prev 2007;16:2686-96.

14. Loh K, Chia JA, Greco S, Cozzi SJ, Buttenshaw RL, Bond $\mathrm{CE}$, et al. Bone morphogenic protein 3 inactivation is an early and frequent event in colorectal cancer development. Genes, Chromosomes and Cancer 2008;47:44960. doi:10.1002/gcc.20552.

15. Haliski J. FDA approves first non-invasive DNA screening test for colorectal cancer. Parsippany, NJ: US Food and Drug Administration 2014;http://www.fda.gov/NewsEvents/Newsroom/PressAnnouncements/ucm409021.htm. 